\title{
POLÍTICAS SOCIOECONÔMICAS DE REAÇÃO À CRISE DA COVID-19 NO MUNICÍPIO DE MARICÁ, RIO DE JANEIRO'1,2
}

\author{
Jéssica Lago da Silva ${ }^{3}$ \\ Rodrigo Carvalho da Silva ${ }^{4}$ \\ Fernando Freitas ${ }^{5}$ \\ Fábio Waltenberg ${ }^{6}$
}

\section{INTRODUÇÃO}

A partir de março de 2020, a Prefeitura de Maricá tomou uma série de açôes para tentar mitigar o impacto socioeconômico da Covid-19 sobre a população, sobretudo sobre a mais vulnerável. Este texto faz um balanço, ainda no calor do momento, dos alcances e limites dessas açóes, procurando extrair liçôes para Maricá e, possivelmente, para outros locais.

O enquadramento da análise apoia-se em um longo debate sobre desenho de políticas assistenciais. Todas as variantes de políticas focalizadas apresentam dificuldades - conceituais, práticas, financeiras - envolvendo obstáculos na identificação e no registro de beneficiários, efeitos colaterais, como estigma ou armadilhas (da pobreza, do desemprego, da informalidade), ineficiências horizontal (nem todos os pobres são beneficiados) e vertical (não pobres acabam beneficiados) e ressentimentos diversos. Dificuldades essas que tendem a se intensificar em momentos de crise.

Um caminho alternativo, explorado em termos teóricos, mas ainda pouco testado, são as políticas de transferências universais, que preconizam que os benefícios sejam distribuídos a todos os cidadãos, individualmente, sem verificação de renda e sem exigência de contrapartidas. Com a pandemia do coronavírus, devastadora no plano da saúde e no plano socioeconômico, e diante das dificuldades que permeiam políticas focalizadas, as transferências universais ganharam espaço no debate.

O município de Maricá tem algumas particularidades que devem ser destacadas. Primeiro, é uma prefeitura com boa dotação orçamentária, o que lhe dá graus de liberdade para açóes emergenciais a que poucos entes federados brasileiros têm acesso. Segundo, assim como outros

\footnotetext{
1. DOI: http://dx.doi.org/10.38116/bmt69/economiasolidaria3

2. Este trabalho foi elaborado como parte de pesquisa de iniciação científica número IC 190760/UFF, orientada por Fábio Waltenberg, tendo Jéssica Lago da Silva como bolsista do Conselho Nacional de Desenvolvimento Científico e Tecnológico (CNPq), a quem agradece, e Rodrigo Carvalho da Silva como voluntário, e também contou com a participação de Fernando Freitas, integrante da equipe da Universidade Federal Fluminense (UFF) envolvida na avaliação do programa Renda Básica de Cidadania de Maricá. Uma versão mais curta será publicada como capítulo de livro em preparação: Waltenberg, 2020 (no prelo). Uma versão mais longa foi divulgada como texto para discussão do Centro de Estudos sobre Desigualdade e Desenvolvimento da Universidade Federal Fluminense (Cede/UFF). Disponivel em: <https://bit.ly/3eRiSwy>.

3. Pesquisadora do Cede/UFF. E-mail: <jessicalagosilva@gmail.com>.

4. Pesquisador do Cede/UFF. E-mail: <rodrigocarvalhosilva@id.uff.br>.

5. Pesquisador do Cede/UFF. E-mail:<fernando.jgomes.freitas@gmail.com>.

6. Professor do Departamento de Economia da UFF. E-mail: <fdwaltenberg@id.uff.br>.
} 
governos espalhados pelo mundo, a Prefeitura de Maricá foi obrigada a tomar medidas de forma tempestiva, em meio à crise, no entanto, contava, como se verá, com uma vantagem determinante: uma estrutura de transferências de renda já montada, viabilizada pela ação de um banco comunitário. Terceiro, Maricá conta com uma política única no mundo todo, a Renda Básica de Cidadania, estruturada em conjunto com outras açóes de economia solidária no município, como o Banco Comunitário e a moeda social Mumbuca. Embora não seja efetivamente uma política universal - visto que alcança cerca de $25 \%$ da população -, a Renda Básica de Cidadania compartilha duas características importantes com as propostas de renda básica universal: a incondicionalidade e a individualidade. É, portanto, uma política sui generis, por ser híbrida, a meio caminho entre aquelas de tradição focalizadora e as universalistas. Por fim, é interessante observar Maricá porque, enquanto o sistema da Renda Básica de Cidadania se mostrou prático para viabilizar a distribuição de Auxílio Emergencial, dificuldades foram enfrentadas para apoiar outros públicos, como os empreendimentos de economia solidária, microempreendedores e trabalhadores autônomos.

\section{TRANSFERÊNCIAS DE RENDA FOCALIZADA E UNIVERSAIS: DESAFIOS E DILEMAS}

Assim como nos Estados de bem-estar social do mundo desenvolvido, também no Brasil criou-se um amplo conjunto de instrumentos para transferências assistenciais, sobretudo, mas não apenas, no âmbito do governo federal: benefícios assistenciais não contributivos a idosos pobres ou a adultos inaptos ao trabalho (como o Benefício de Prestação Continuada - BPC), benefícios assistenciais a adultos em idade laboral, aptos ao trabalho e pobres (como o Programa Bolsa Família - PBF), créditos tributários ou complementos salariais a trabalhadores formais de baixa renda (como o Abono Salarial), gastos tributários (como deduçóes no Imposto de Renda para despesas com saúde e educação), benefícios com uso predeterminado (como valesalimentação), entre outros. Para cada um deles, há uma justificativa diferente, um critério de elegibilidade diferente, contrapartidas (ou "condicionalidades") diferentes, um valor diferente. E cada benefício tem uma operacionalização específica, apoiada em cadastros próprios, cada um dos quais gerido por ministério, secretaria ou subsecretaria diferente.

Dentro da lógica de benefícios assistenciais focalizados, são três os principais critérios para avaliar a qualidade de um programa (Barr, 2012): i) se o valor do benefício é suficiente para amenizar a pobreza; ii) se o custo é bem controlado (somando desembolso com os benefícios em si e os custos de administração e implementação do programa); e iii) se é bem focalizado no público-alvo. Dilemas são inevitáveis. Por exemplo, aumentar o valor faz sentido sob o prisma do primeiro critério, mas pressiona o segundo e o terceiro, pois um benefício mais interessante atrairá mais gente, inclusive fora do público-alvo, e exigirá esforços - isto é, gastos - para se obter informaçóes, monitorar, fiscalizar, implementar.

Esses dilemas conduzem - há décadas - a uma discussão em torno do melhor desenho de políticas focalizadas, com destaque para três categorias (Besley e Kanbur, 1993; Barr, 2012): i) focalização clássica, que consiste em transferir recursos apenas aos comprovadamente pobres; 
ii) focalização por indicadores, que beneficia pessoas que apresentam características sabidamente correlacionadas com a pobreza - ainda que não perfeitamente correlacionadas -, como a presença ou a quantidade de crianças no domicílio; e iii) autofocalização, apoiada em valores concedidos automaticamente - às vezes até inadvertidamente - como no momento do consumo (desoneração da cesta básica), do pagamento de impostos (deduçôes no Imposto de Renda), ou pela situação no mercado de trabalho (Abono Salarial pago aos formais de baixa renda).

Há desvantagens associadas a cada uma delas. Contra a focalização clássica: não é simples nem barato diferenciar pobres de não pobres; pode ser contraproducente estabelecer fronteira rígida entre elegíveis e não elegíveis com base na renda, gerando estigma ou armadilhas (da pobreza, do desemprego, da informalidade). Contra a focalização por indicadores e a autofocalização: sempre haverá erros, com benefícios transbordando da população-alvo (ineficiência vertical) e com exclusão de parte da população-alvo (ineficiência horizontal). Contra focalização de qualquer tipo: sentimentos de injustiça ou de hostilidade por parte dos não beneficiários.

Um caminho alternativo, bastante explorado em termos teóricos há muitos anos, ainda foi pouco testado na prática: as políticas de transferências universais, que preconizam que os benefícios sejam distribuídos a todos os cidadãos, individualmente, sem verificação de renda e sem exigência de contrapartidas (Van Parijs e Vanderborght, 2017). No Brasil, a Lei no 10.835/2004 criou a Renda Básica de Cidadania, nunca implementada de fato.

Limitando-nos aqui a um contraponto aos limites das políticas focalizadas, já descritos, pode-se dizer que, ao não ser mais necessário diferenciar elegíveis de não elegíveis (exceto não residentes), políticas de transferência universais reduziriam custos de administração, por meio de esforços e gastos menores com obtenção de informações, monitoramento, fiscalização e operacionalizaçáo das transferências. Seriam desarmadas as armadilhas da pobreza, do desemprego ou da informalidade - com benefício universal, não haveria dilema entre, de um lado, a opção de manter-se pobre, desempregado ou informal com benefício, e, de outro lado, a opçáo de tornar-se náo pobre (por quanto tempo?), empregado (por quanto tempo?) e formal (por quanto tempo?), mas sem benefício. Em outras palavras, deixaria de existir qualquer desincentivo a que uma pessoa transitasse para uma faixa de renda laboral mais elevada, do desemprego ao emprego, ou da informalidade à formalidade, meramente pelo temor da insegurança econômica associada à perda de um benefício.

\section{DESENVOLVIMENTO DO PROGRAMA RENDA BÁSICA DE CIDADANIA ANTES DA PANDEMIA}

A principal política aqui abordada é fruto de evoluçóes graduais no programa de transferência de renda da Prefeitura de Maricá, a qual, após sua mudança mais significativa em 2019, transformou-se no maior programa de renda básica da América Latina (Ferreira e Katz, 2020). Criados em junho de 2013 através da Lei no 2.448/2013, a moeda social Mumbuca e o Banco Comunitário Popular, posteriormente Banco Mumbuca, tinham como objetivo o combate às desigualdades sociais e o fomento ao desenvolvimento econômico e social 
das comunidades, buscando erradicar a pobreza e gerar emprego e renda para as camadas carentes do município.

O projeto previa uma política de renda mínima para a população mais pobre, realizada através de um cartão de débito contendo 70 mumbucas $(\mathrm{R} \$ 70,00)$, o benefício só poderia ser gasto no município em estabelecimentos que aceitassem a moeda social. Para a época, diversas eram as condições de elegibilidade e condicionalidades a serem cumpridas pelas famílias para participar do programa, como comprovaçáo de vacinação dos dependentes de zero a seis anos de idade e matrícula de crianças em escolas. Além disso, para se tornar beneficiária, a família deveria ter renda até 1 salário mínimo - SM (Mais..., 2013). Bem distante de sua estrutura atual, a política exigia condicionalidades, era focalizada em famílias muito pobres e apresentava baixa cobertura populacional.

A fase inicial da política foi marcada por diversas etapas de cadastramento, com postos espalhados pela cidade, onde os possíveis beneficiários deveriam apresentar sua documentaçáo. Ao final de 2014, foi realizada atualização de informaçôes sobre as famílias cadastradas, o valor da renda mínima foi reajustado para 85 mumbucas (Bolsa..., 2014).

No final do ano de 2015, houve uma expansão das políticas de transferência de renda no município. Através das Leis n $\underline{\text { os }} 2.652$ e 2.662, o programa focalizado anterior deu lugar a três programas de renda mínima para públicos específicos, com o valor do benefício sendo mantido em 85 mumbucas. De forma complementar, o público das três políticas de renda mínima passou a ser elegível também para uma renda adicional de 10 mumbucas, denominada renda básica. No total, o benefício médio das políticas tornou-se 95 mumbucas para cada domicílio.

As leis modificaram profundamente características da transferência de renda municipal, alterando: i) critério de elegibilidade pela renda familiar: passou de até 1 SM para até 3 SMs; ii) público-alvo: a modalidade Gestante passou a contemplar gestantes durante a gravidez e até a criança completar um ano; a modalidade Jovem Solidário, visando jovens entre 14 e 29 anos com baixa renda; e o Renda Minima Mumbuca destinado a responsáveis familiares com renda inferior a 3 SMs; iii) base de dados: antes recorria-se apenas a um cadastro municipal, após a mudança, o Cadastro Único também passou a ser usado.

Em maio de 2017, as políticas de renda mínima foram reajustadas para o valor médio de 110 mumbucas, enquanto a renda básica passou para 20 mumbucas. Assim, o valor passou para 130 mumbucas por domicílio. As mudanças e expansões da política em 2015 e 2017 a tornaram mais abrangente e com valor mais significativo. Entretanto, ainda distante de um benefício incondicional, universal e individual, uma vez que as políticas de renda mínima exigiam cumprimento de condicionalidade e apenas famílias em grupos populacionais específicos eram elegíveis.

Em junho de 2019, os três programas existentes foram unificados no Programa de Renda Básica de Cidadania, através da Lei no 2.869. O benefício no valor de 130 mumbucas mensais ( $\mathrm{R} \$ 130,00)$ passa a ser destinado a todos os indivíduos com renda familiar mensal de até 3 SMs morando na cidade há pelo menos três anos. 
Redesenhado diversas vezes, em termos de cobertura, valor e regras, o benefício tornou-se o que é hoje, cumprindo quase plenamente dois dos três princípios idealizados por uma política de renda básica: incondicionalidade e individualidade. Desde dezembro de 2019, mais de 42 mil pessoas recebem o benefício, e pretende-se alcançar toda a população.

Apesar de não exigir nenhuma condicionalidade, o programa restringe o uso do auxílio aos limites territoriais da cidade. De acordo com informaçôes do Banco Mumbuca, de junho de 2020, o cartáo de débito é aceito por cerca de 5.700 estabelecimentos credenciados - formais ou informais - possibilitando que o recurso circule exclusivamente no município, contribuindo para o desenvolvimento local.

O avanço advém do fato de o benefício ter se tornado individual em 2019. Antes, com benefício concedido apenas ao responsável familiar, as famílias beneficiárias tinham direito a 130 mumbucas para serem divididas entre todos os seus membros, o que tornava o benefício insuficiente no combate à pobreza. Atualmente, cada integrante da família tem direito ao benefício de 130 mumbucas, possibilitando que uma família com quatro pessoas e que receba outro benefício governamental, como o PBF, acumule cerca de $\mathrm{R} \$ 700,00$ mensais, mais de meio salário mínimo; o valor de 130 mumbucas por pessoa é significativo, levando em consideração que uma linha da pobreza per capita usual - a do PBF - é atualmente de R\$ 178,00 por mês (Ferreira e Katz, 2020).

A política de Renda Básica de Cidadania de Maricá apresenta elementos importantes, que a aproximam de uma política de renda básica preconizada na literatura, além de ter elementos pioneiros, como o fato de o pagamento ser feito por meio de um cartáo de um banco comunitário, para uso exclusivo no município.

\section{RESPOSTA DA PREFEITURA DE MARICÁ À CRISE PROVOCADA PELA PANDEMIA}

O cenário pandêmico dos últimos meses exigia respostas rápidas de países e de seus entes subnacionais, ${ }^{7}$ e Maricá foi capaz de mobilizar seu amplo sistema de proteção social, construído nos últimos anos, para mitigar os efeitos negativos da pandemia para seus habitantes.

Antes mesmo do primeiro caso confirmado de Covid-19 no município, a prefeitura passou a adotar diversas medidas para proteger sua populaçáo, como fechamento de escolas, restrição de funcionamento de comércios e suspensão de atividades não essenciais. (Ambrósio, 2020b; Zarôr, 2020b; Silva, 2020). No dia 18 de março de 2020, declarou-se estado de emergência em saúde pública no município de Maricá.

Em seguida, o Decreto no 499 autorizou a antecipação do Abono Natalino de beneficiários do programa de Renda Básica de Cidadania, no valor de 130 mumbucas por indivíduo. A medida injetou cerca de 5,4 milhóes de mumbucas na economia local. Em apenas uma

7. No momento em que escrevemos, ao menos 190 países ao redor do mundo adotaram políticas visando mitigar os efeitos econômicos da pandemia de Covid-19. As medidas adotadas variam entre: políticas de mercado de trabalho (126), de seguridade social (254) e, na maioria dos casos, de assistência social (559). Os governos buscaram aliviar a crise para os mais pobres, proteger empregos e renda, e assegurar direitos trabalhistas, como licença remunerada e licença médica (Gentilini, 2020). Ver Silva, Silva e Waltenberg (2020) para uma síntese. 
semana, no dia 25 de março de 2020, os créditos já estavam disponíveis para os beneficiários (Boletim 6..., 2020). Também seriam distribuídas, por três meses, cestas básicas para famílias de alunos da rede pública que, devido à suspensão das aulas, ficaram sem alimentação oferecida nas escolas (Ferreira, 2020). Em junho de 2020, devido à permanência do estado de emergência, a distribuição das cestas foi prorrogada por mais três meses.

No dia 21 de março de 2020, a prefeitura anunciou um pacote de $\mathrm{R} \$ 80$ milhóes, visando fomentar a economia do município e reduzir os efeitos negativos da crise. Prevista pelo pacote, a Lei no 2.921 instituiu o aumento da transferência de 130 mumbucas mensais para 300 mumbucas mensais, por três meses (Zarôr, 2020a). Em junho de 2020, devido à manutençáo do estado de emergência, a medida foi prorrogada por mais três meses. O pacote também contava com uma linha de crédito para empresários da cidade, que poderia chegar a $\mathrm{R} \$ 50$ mil, com pagamento previsto apenas para janeiro de 2021. Por fim, a prefeitura adiou a cobrança do Imposto Sobre Serviços de Qualquer Natureza (ISS) fixo dos comerciantes e do Imposto Predial e Territorial Urbano (IPTU) dos idosos (acima de 60 anos) até que a situação fosse normalizada.

Pode-se comparar a ampliação do valor da renda básica como uma medida emergencial com políticas adotadas em outras cidades, como Salvador, que optou pela distribuição de vales. No caso maricaense, garante-se liberdade na escolha de qual cesta de bens ou serviços consumir. Os recursos podem custear a compra de alimentos, é claro, mas também de produtos de higiene e limpeza, vestuário, serviços de barbearia ou de manicure, entre outros. Dessa forma, permite maior circulação monetária na moeda mumbuca, beneficiando empreendedores locais, sobretudo os de menor porte. No modelo soteropolitano, o uso é restrito a determinada cesta de bens - gás de cozinha e alimentos da cesta básica -, de forma que o impacto no aumento da demanda é estritamente setorizado.

Em que pesem os acertos propiciados pela estrutura de Renda Básica de Cidadania, a prefeitura não contava com uma política destinada exclusivamente a trabalhadores informais. O município precisou criar, através da Lei no 2.920, de 24 de março de 2020, um Programa de Amparo ao Trabalhador (PAT). O programa previa o pagamento durante três meses, e passível de prorrogaçáo por mais três meses, de valor equivalente a 1 SM para cerca de 12 mil trabalhadores autônomos, profissionais liberais e informais. Para receber o benefício, o trabalhador teria de morar no município, comprovar renda familiar mensal de até $\mathrm{R} \$ 5$ mil e comprovar que suas atividades foram afetadas. ${ }^{8} \mathrm{O}$ volume de benefícios a ser concedido inicialmente seria de 12 mil, havendo ordem de prioridade na concessão (Ambrósio, 2020a), valor que se revelou subestimado, visto que as solicitaçóes foram mais que o dobro, levando a prefeitura a ampliar o programa e adotar um teto de 26.518 (Ambrósio, 2020c).

8. Ao se cadastrar on-line, o trabalhador deveria anexar documentação que comprovasse sua atividade no município, como autorização de exercício de atividade remunerada, cadastro do microempreendedor individual, entre outros. Foi proibida a concessão do benefício para funcionários públicos e profissionais que já possuíssem renda além da atividade afetada. Além disso, o benefício não seria concedido a mais de um membro da família ou para aqueles que recebessem seguro-desemprego. 0 tempo previsto para análise do cadastro do informal era de aproximadamente quinze dias. 
Em 13 de maio de 2020, através da Lei no 2.929, a prefeitura criou o Programa de Amparo ao Emprego (PAE), que buscava proteger trabalhadores do mercado formal. Microempresas com até 49 funcionários e microempreendedores individuais (MEIs) receberiam, em reais e não em mumbucas, montante equivalente a $1 \mathrm{SM}$ por funcionário. Com previsão de duração de três meses, a política beneficiou cerca de 250 empresas. Para recebê-lo, os empregadores tinham de se cadastrar em plataforma on-line e comprovar mensalmente a folha salarial, não podendo demitir seus funcionários por três meses após o fim dos benefícios. Em caso de eventual sobreposição da política federal de apoio ao emprego (Medida Provisória no 936) com a política municipal (Lei no 2.939), o valor do benefício seria ajustado de acordo com parâmetros pré-definidos.

\section{ALCANCES E LIMITES DA RESPOSTA DE MARICÁ, E OBSERVAÇÕES PARA O FUTURO}

A pandemia de Covid-19 disseminou uma crise sanitária de proporçóes inéditas. Mas também dificuldades socioeconômicas de dimensão incalculável no momento em que escrevemos este texto, mas que certamente revelarão ser muito profundas, senão devastadoras. ${ }^{9}$ Países e entes subnacionais mundo afora foram levados a adotar medidas emergenciais de proteção da renda e do emprego, a fim de amenizar os efeitos mais dramáticos da crise, sobretudo para as populações mais vulneráveis. Maricá não foi exceção; ao contrário, em um curto espaço de tempo tomou uma série de medidas bastante ousadas.

A maioria dos países, estados e municípios valeu-se de estruturas e programas assistenciais vigentes, cuja lógica é de focalização. Valores de benefícios pagos aos beneficiários foram elevados, o que está de acordo com o primeiro critério de avaliação de políticas focalizadas. Quando havia informação disponível em cadastros, a cobertura foi expandida para incluir no rol de beneficiários pessoas antes não beneficiárias, mas com características de vulnerabilidade.

Esse voluntarismo de governos nacionais e subnacionais esbarrou em dificuldades práticas, decorrentes da própria lógica de focalização. Primeiro, muita energia foi gasta - isto é, tempo e dinheiro - para identificar beneficiários e para separar elegíveis de não elegíveis. Um exemplo disso é a dificuldade enfrentada pelo governo federal para identificar os beneficiários do Auxílio Emergencial.

Segundo, critérios muitas vezes arbitrários foram impostos, como de idade ou renda, ${ }^{10}$ excluindo famílias vulneráveis que não se enquadram nas condições definidas. Decisóes como estas podem cultivar ressentimentos com relaçáo a políticas assistenciais, minar o apoio popular a políticas de redistribuição de renda e enfraquecer as coalizóes políticas que as implementam.

9. Diversos números podem ser usados para atestar a dimensão do tamanho da crise. A projeção mais recente do Fundo Monetário Internacional (FMI) é de queda de 9,1\% do produto interno bruto (PIB) brasileiro. 0 mercado de trabalho brasileiro, em particular, já foi muito afetado. 0 Instituto Brasileiro de Geografia e Estatística (IBGE) indica que a taxa de desocupação chegou a 12,6\% no trimestre encerrado em abril, com 12,8 milhões de brasileiros desempregados. A população ocupada caiu 5,2\%, em relação ao trimestre anterior, com perda de 4,9 milhões de postos de trabalho.

10. Por exemplo, em algumas modalidades de auxílios emergenciais em Portugal e na Itália, benefícios seriam concedidos a famílias com crianças até 12 anos, mas não para aquelas com crianças de 13 anos (Silva, Silva e Waltenberg, 2020). Outro exemplo são benefícios concedidos, no Brasil, a famílias com renda per capita até meio salário mínimo, ou renda total de até três salários mínimo, mas não para aquelas cuja renda é superior em poucos reais a esses limiares. 
Terceiro, observou-se imensa dificuldade para fazer os benefícios chegar à ponta, às mãos dos beneficiários. Exemplo claro disso foram os inúmeros obstáculos enfrentados por pessoas que cumpriam todos os requisitos para receber o Auxílio Emergencial do governo federal brasileiro. Houve problemas para acessar o aplicativo, para análise das solicitações, para transferência do dinheiro aos bancos, pedidos de elegíveis foram negados, houve formação de filas justamente quando a Organização Mundial da Saúde (OMS) recomendava isolamento.

Em quarto e último lugar, apesar de louváveis os esforços para proteger os mais vulneráveis mundo afora, muitas pessoas inelegíveis aos programas assistenciais no mês de abril, maio ou junho de 2020 - por ainda manterem emprego formal, por exemplo - talvez já estejam desempregadas em julho, agosto ou setembro de 2020. E isso sem que os beneficiados pelas primeiras medidas estejam em condiçóes de deixar de ser assistidos. Em tal cenário, bastante plausível, os governos estão sendo obrigado a pensar em uma segunda onda de medidas de proteçáo, ampliando a parcela beneficiada e flexibilizando ainda mais a natureza focalizada dessas políticas.

A Prefeitura de Maricá fez um bom trabalho, ao combinar políticas de naturezas diferentes, com uma grande rapidez na resposta, alinhando-se assim às melhores práticas internacionais. Também foi capaz de se adaptar muito bem à permanência prolongada do estado de emergência, ao prorrogar as políticas adotadas e expandir sua cobertura. Concretamente, como já mencionado, a prefeitura prorrogou por três meses, de julho a setembro de 2020, a distribuição das cestas básicas, o PAT e o valor mais generoso do benefício Renda Básica de Cidadania. Quanto ao PAE, esta é uma medida por excelência de resposta à longa duração da crise, pois teve início somente em meados de junho de 2020, e alcançou público anteriormente não afetado, mas que, com a extensão da crise, observou seus empregos em risco.

Para que o conjunto de políticas de Maricá pudesse ocorrer, contribuíram fatores destacados na introdução deste trabalho, como uma boa disponibilidade orçamentária. Mas uma vantagem foi determinante e precisa ser novamente destacada: a existência de uma estrutura previamente montada de transferências de renda, viabilizada pela ação de um banco comunitário. Para acionar as medidas que atenderam aos beneficiários da Renda Básica de Cidadania, só foi necessário tomar a decisão política de incrementar o valor dos benefícios, medida implementada em poucos dias e sem registro de maiores dificuldades. Essa facilidade de implementação confirma as impressóes de um dos mais importantes proponentes de políticas universais, o filósofo belga Philippe Van Parijs, que, em entrevista recente destacou que as dificuldades enfrentadas na implementação de medidas assistenciais emergenciais:

aumentam nossa consciência de quão mais bem equipadas nossas sociedades e nossas economias estariam para enfrentar desafios como esse se houvesse uma renda básica incondicional permanente. Se fosse esse o caso, não haveria pessoas sem renda, aguardando a implementação de esquemas ad hoc ou tentando descobrir como poderiam acessar programas existentes que nunca sonharam em precisar (Five..., 2020, tradução nossa). 
A Renda Básica de Cidadania de Maricá compartilha com as propostas teóricas de renda básica duas características importantes: a incondicionalidade e a individualidade (embora esta última não seja plena, como veremos adiante). Mas não é efetivamente universal, visto que alcança pouco mais de 42 mil pessoas, ou cerca de 25\% da população de Maricá. Como se trata de pessoas inscritas no Cadastro Único do governo federal, é quase certo que são todas de baixa renda, socialmente vulneráveis, de modo que a política alcança bons resultados na focalização vertical. Contudo, há limitaçôes. Primeiro, sabe-se que há ineficiência horizontal, visto que há cerca de 60 mil maricaenses no Cadastro Único, mas 30\% deles não estão inscritos no programa Renda Básica de Cidadania, de modo que uma parte da população vulnerável não estava protegida antes da pandemia, e não pôde ser diretamente beneficiada durante esta crise. Quanto mais longa e aguda for a crise, maiores serão as consequências negativas desta desproteção. Além disso, pode-se supor que, entre os 100 mil maricaenses não inscritos no cadastro, muitos estejam passando por dificuldades nesse momento.

Enquanto o sistema da Renda Básica de Cidadania se mostrou muito prático para a viabilização de apoio emergencial, dificuldades foram enfrentadas em outras áreas, como nas políticas destinadas a trabalhadores informais e microempreendedores (PAT) e no apoio aos trabalhadores formais (PAE). A prefeitura teve de criar uma plataforma de cadastro, bases de dados, divulgar a política e seu funcionamento, além de criar um comitê de funcionários para avaliar os pedidos de ambas as políticas. Embora o planejamento tenha funcionado, não é o procedimento ideal pela demora para que o benefício chegue às pessoas em uma situação de crise.

A partir do que foi observado, assim que terminada a fase aguda da crise do coronavírus, é desejável que a prefeitura expanda o cadastro usado para concessão da Renda Básica de Cidadania tanto quanto possível, de preferência abrangendo toda a população, mesmo que inicialmente nem todos possam receber o benefício - por exemplo, por limitaçóes de ordem orçamentária ou por ser ano eleitoral. Essa expansão do cadastramento seria um passo importante para superar dificuldades associadas a políticas focalizadas. Idealmente, esse cadastro único municipal conteria um painel de informaçóes bastante completo sobre todos os maricaenses, o qual poderia ser mobilizado por diferentes secretarias para diferentes fins.

A Renda Básica de Cidadania de Maricá já é incondicional, como preconiza a literatura, e deve manter-se assim. Mas ainda náo é universal, nem plenamente individualizada. Quanto à individualização, assim que possível, a prefeitura poderia caminhar no sentido de fornecer um cartão individual a cada beneficiário e não mais transferir os benefícios de uma família para um único cartão - essa mudança seria importante para assegurar o maior grau possível de autonomia e liberdade individual. Recursos destinados a crianças, adolescentes e adultos incapazes continuariam sendo pagos a um membro da família, segundo regras a definir.

No momento em que julgasse adequado, a prefeitura poderia então avançar na direção da efetiva universalização da Renda Básica de Cidadania, em razão dos argumentos já desenvolvidos na literatura sobre renda básica universal e brevemente resumidos na seção 2 . Seria outro passo fundamental para a superação dos limites associados a políticas focalizadas. 
O canal aberto por uma concessão regular de uma renda universal, incondicional e individual tem a vantagem de poder ser acionado em momentos de crise, em uma combinaçáo de elementos da lógica de programas universais com a de programas focalizados. Quanto melhor a qualidade do cadastro, mais flexibilidade terá o governo para se valer dele para direcionar medidas a grupos específicos da população, em situaçôes e condições particulares.

\section{REFERÊNCIAS}

AMBRÓSIO, M. Auxílio ao autônomo e ao informal no programa de amparo ao trabalhador tem regras definidas. Portal Prefeitura de Maricá, Maricá, 28 mar. 2020a. Disponível em: <https://bit.ly/3gkyVmR>. Acesso em: 6 maio 2020.

. Secretaria confirma primeiro caso de coronavírus em Maricá. Portal Prefeitura de Maricá, Maricá, 29 mar. 2020b. Disponível em: <https://bit.ly/3imcXBt>. Acesso em: 6 maio 2020.

Programa de Amparo ao Trabalhador é ampliado pela prefeitura. Portal Prefeitura de Maricá, Maricá, 20 abr. 2020c. Disponível em: <https://bit.ly/3gjKM4D>. Acesso em: 6 maio 2020 .

BARR, N. Economics of the welfare state. 5 ed. Oxford: Oxford University Press, 2012.

BESLEY, T.; R. KANBUR. The principles of targeting. In: LIPTON, M.; GAAG, J. V. D. (Eds.). Including the poor: proceedings of a symposium. Washington: World Bank, 1993.

Boletim 6: medidas contra coronavírus. Portal Prefeitura de Maricá, Maricá, 22 mar. 2020. Disponível em: <https://bit.ly/38hVd5E>. Acesso em: 6 maio 2020.

BOLSA Mumbuca atinge 14 mil beneficiados. Portal Prefeitura de Maricá, Maricá, 11 nov. 2014. Disponível em: <https://bit.ly/2NNcKJQ>. Acesso em: 6 maio 2020.

FERREIRA, A. Prefeitura divulga cronograma para entrega de cestas básicas. Portal Prefeitura de Maricá, Maricá, 5 abr. 2020. Disponível: <https://bit.ly/38mf8R>. Acesso em: 6 maio 2020.

FERREIRA, L.; KATZ, P. What a solidarity economy looks like. Boston Review, 9 de abr. de 2020. Disponível em: <https://bit.ly/2NNoY4V>. Acesso em: 6 maio 2020.

FIVE Questions to philosopher Philippe Van Parijs on basic income and the coronavirus. The Brussels Times, 2 Apr. 2020. Disponível em: <https://bit.ly/2Vyvkt9>. Acesso em: 1은 maio 2020.

GENTILINI, U. et al. Social protection and jobs responses to Covid-19: a real-time review of country measures. World Bank, 2020. 477p.

MAIS de 400 famílias de baixa renda já estão cadastradas no Bolsa Mumbuca. Jornal Prefeitura de Maricá, v. 5, n. 427, 16 dez. 2013. Disponível em: <https://bit.ly/2YMazwd>. Acesso em: 6 maio 2020.

SILVA, L. F. Boletim 1: ações de prevenção ao coronavírus. Portal Prefeitura de Maricá, Maricá, 17 mar. 2020. Disponível em: <https://bit.ly/3g8dhSG>. Acesso em: 6 de maio de 2020.

SILVA, J.; SILVA, R.; WALTENBERG, F. Abono Salarial Emergencial para apoiar trabalhadores formais de baixa renda. Rio de Janeiro: Cede, 2020. (Texto para Discussão, n. 150). Disponível em: <https://bit.ly/3gh 1 zFe $>$. 
VAN PARIJS, P. V.; VANDERBORGHT, Y. Basic income: a radical proposal for a free society and a sane economy. Londres: Harvard University Press, 2017.

WALTENBERG, F. Alcances e limites das ações de combate à pobreza da Prefeitura de Maricá em resposta à crise da Covid-19. In: INSTITUTO MUNICIPAL DE INFORMAÇÓEES E PESQUISA DARCY RIBEIRO. Estudos Maricaenses: o município de Maricá em debate, Maricá: IDR, 2020. (No prelo).

ZARÔR, R. Boletim 18: coronavírus - 3/4. Portal Prefeitura de Maricá, Maricá, 3 abr. 2020a. Disponível em: <https://bit.ly/2VxnFv9>. Acesso em: 6 maio 2020.

Boletim 44: 29/4. Portal Prefeitura de Maricá, Maricá, 29 abr. 2020b. Disponível em: <https://bit.ly/2YPayI4>. Acesso em: 6 maio 2020. 
